\title{
Hemoprotozoa and Anaplasma spp. in rodents and shrews of Bangladesh
}

\author{
Islam, S. ${ }^{1,2}$, Rahman, M.K. ${ }^{1,2}$, Ferdous, J. ${ }^{1,2}$, Rahman, M. ${ }^{3}$, Akter, S. ${ }^{4}$, Faraque, M.O. ${ }^{5}$, Chowdhury, M.N.U. ${ }^{6}$, \\ Hossain, M.A. ${ }^{3}$, Hassan, M.M. ${ }^{5}$, Islam, A. ${ }^{7}$ and Islam, A. ${ }^{2^{*}}$ \\ ${ }^{1}$ Institute of Epidemiology, Disease Control and Research (IEDCR), Mohakhali, Dhaka-1212, Bangladesh \\ ${ }^{2}$ EcoHealth Alliance, New York, NY10001-2320, USA \\ ${ }^{3}$ Department of Parasitology and Pathology, Faculty of Veterinary Medicine, Chattogram Veterinary and \\ Animal Sciences University, Khulshi, Chattogram-4225, Bangladesh \\ ${ }^{4}$ Department of Medicine and Surgery, Faculty of Veterinary Medicine, Chattogram Veterinary and Animal \\ Sciences University, Khulshi, Chattogram-4225, Bangladesh \\ ${ }^{5}$ Department of Physiology, Biochemistry and Pharmacology, Faculty of Veterinary Medicine, \\ Chattogram Veterinary and Animal Sciences University, Khulshi, Chattogram-4225, Bangladesh \\ ${ }^{6}$ Bangladesh Forest Department, Ministry of Environment and Forests, Government of the People's Republic \\ of Bangladesh, Bangladesh \\ ${ }^{7}$ International Centre for Diarrheal Disease Research, Bangladesh (icddr,b), Mohakhali, Dhaka-1212, \\ Bangladesh \\ *Corresponding author e-mail: arif@ecohealthalliance.org \\ Received 14 October 2019; received in revised form 9 August 2020; accepted 10 August 2020
}

\begin{abstract}
Hemoprotozoans are important pathogens of animals and humans, among which some species have zoonotic significance. The prevalence of different hemoprotozoa and Anaplasma spp. in larger mammals have been reported from different regions of the world. But, very few studies have been conducted to estimate the prevalence of hemoprotozoa in rodents and shrews of South-East Asia. The study assessed the prevalence of hemoprotozoa and Anaplasma spp. in rodents and shrews of Bangladesh. Blood samples $(n=451)$ were collected from rodents and shrews between June 2011 and June 2013 and July-December 2015 from 4 land gradients of Bangladesh. Giemsa-stained blood smears revealed that $13 \%$ of animals were harboring hemoprotozoa (4.7\% Babesia spp., 0.67\% Plasmodium spp.), and Anaplasma spp. (7.5\%). The study may serve as a guide for future hemoparasitic research of rodents and shrews.
\end{abstract}

\section{INTRODUCTION}

Small mammals are the key mammalian group to survive in diverse environments in the world (Polacikova, 2013). Rodents are the largest group among the small mammals, with extensive habitat range from sub-terrestrial to terrestrial. Two rodent species, Mus musculus (house mouse) and Rattus rattus (black rat/house rat) and one shrew species, Asian house shrew (Suncus murinus) are commonly found in Bangladesh. They are commensal with humans and found near human habitation and other synanthropic habitats such as rice fields and grain warehouses (Veciana et al., 2012).

Rodents and shrews play an important role as a reservoir host and final host of many infectious zoonotic organisms (Gratz, 1994). More than 20 well-known diseases are directly transmitted from rodents to humans, usually through the blood-sucking parasites such as fleas, ticks, and mites (Ellis et al., 1999; Favorov et al., 2000; Wang et al., 2000; Singla et al., 2008; Raj et al., 2009). Urban rats carry many zoonotic pathogens, which can be spread through increased contact with people due to urbanization (Sumangali et al., 2007). Rodents serve as a reservoir 
host for hemoprotozoa and rickettsia, such as Babesia and Anaplasma, respectively (Kallio et al., 2014). Anaplasma spp. was reported in small mammals of Thailand (Thanee et al., 2009), whereas filariae, piroplasms, and trypanosomes were found in rodents of Colombia (Ayala et al., 1973). Moreover, rats, and mice have been found to be infected with Trypanosoma spp. (Sebek, 1975; De Lima et al., 2003; Laakkonen et al., 2003). In a study on 34 Australian bush rats, $32 \%$ of samples were positive for hemoprotozoa with a specific prevalence of 10\% Trypanosoma spp. (McDonogh et al., 2015). Plasmodium spp. (43.3\%) and Trypanosoma spp. (25.2\%) were found in Rattus spp. in Malaysia, and the presence of the hemoprotozoa was influenced by host, age and sex (Alias et al., 2014; McDonogh et al., 2015). Although Babesia spp. was common in field vole/short-tailed vole (Microtus agrestis), it was rarely found in other rodents. Trypanosoma spp., Babesia spp., Hepatozoon spp. and Grahamella spp. were all found in Myodes glareolus (bank vole) and M. agrestis (Wiger, 1979). Hepatozoon spp. was isolated previously from $M$. glareolus with $4.44 \%$ prevalence (Criado-Fornelio et al., 2006). According to a previous study in Nigeria, hemoparasitic prevalence was $75 \%$ in $R$. rattus and $72.22 \%$ in M. musculus; $51.67 \%$ of male and $72.86 \%$ of female rodents were found to be parasitized, and this difference in prevalence was not significant (Ajayi et al., 2006).

Like rats and mice, house shrews can also transmit important pathogens such as Thottapalayam virus (Yadav et al., 2007), Hantavirus (Arai et al., 2007), Toxoplasma gondii (Kijlstra et al., 2008) and Yersinia pestis (plague) (Renapurkar, 1988). They can also harbor hemoprotozoa and can be the source of infection to humans. In one report, hemoprotozoa were less prevalent and less diverse in shrews than in rodents (Karbowiak et al., 2005). Prevalence of hemoprotozoa in the common shrew (Sorexa raneus) and Eurasian water shrew (Neomys fodiens) were reported as 32.5 and $41.2 \%$, respectively (Karbowiak et al., 2005).

Species of hemoprotozoa are related to the habitat selection by host (Thanee et al.,
2009). When habitats are disturbed and the composition of the small mammals' community changes, hemoprotozoa may encounter different hosts near their nest (Nava et al., 2003; Thanee et al., 2009). Humans can be considered as accidental hosts of some hemoprotozoa, acquiring an infection during interaction with the natural enzootic cycle. To date, most of the human cases reported were infected by a tick carrying the rodent hemoprotozoa (Gorenflot et al., 1998). The transmission of parasites is influenced by the close association of rodents and house shrew with humans and livestock and their exposure to blood-sucking arthropods, beetles, cockroaches, and other invertebrates.

There are few published studies concerning animal reservoirs of hemoprotozoa in Asia. The parasitic infections that rodents and shrew harbor and convey to human or animal populations have not been as thoroughly investigated as the microbial infections, especially in Bangladesh. Therefore, the aim of the study was to screen the rodents and shrews of Bangladesh for hemoprotozoa and Anaplasma spp.

\section{MATERIALS AND METHODS}

\section{Study sites and duration}

The study was carried out between June 2011 to June 2013 and July-December 2015 to determine the prevalence of blood protozoa in $R$. rattus, M. musculus and $S$. murinus from four land gradients of Bangladesh, namely Urban (Chattogram metro and Khulshi); Peri-urban (Faridpur and Sitakunda); Rural (Dinajpur, Rajbari, Moulvibazar, Rangpur, Mirsharai, Lalmonirhat, Chakaria, Rangpur and Joypurhat) and Hilly (Rangamati, Khagrachari and Bandarban) (Figure 1).

\section{Data recording, animal capture, and sample collection}

The live rodents and shrews were captured using locally made steel wire traps $(27 \mathrm{~cm} \times$ $13 \mathrm{~cm} \times 13 \mathrm{~cm}$ ) that have proven efficacy in sampling of medium-size and large-size rodents and shrews (Shafiyyah et al., 2012). 


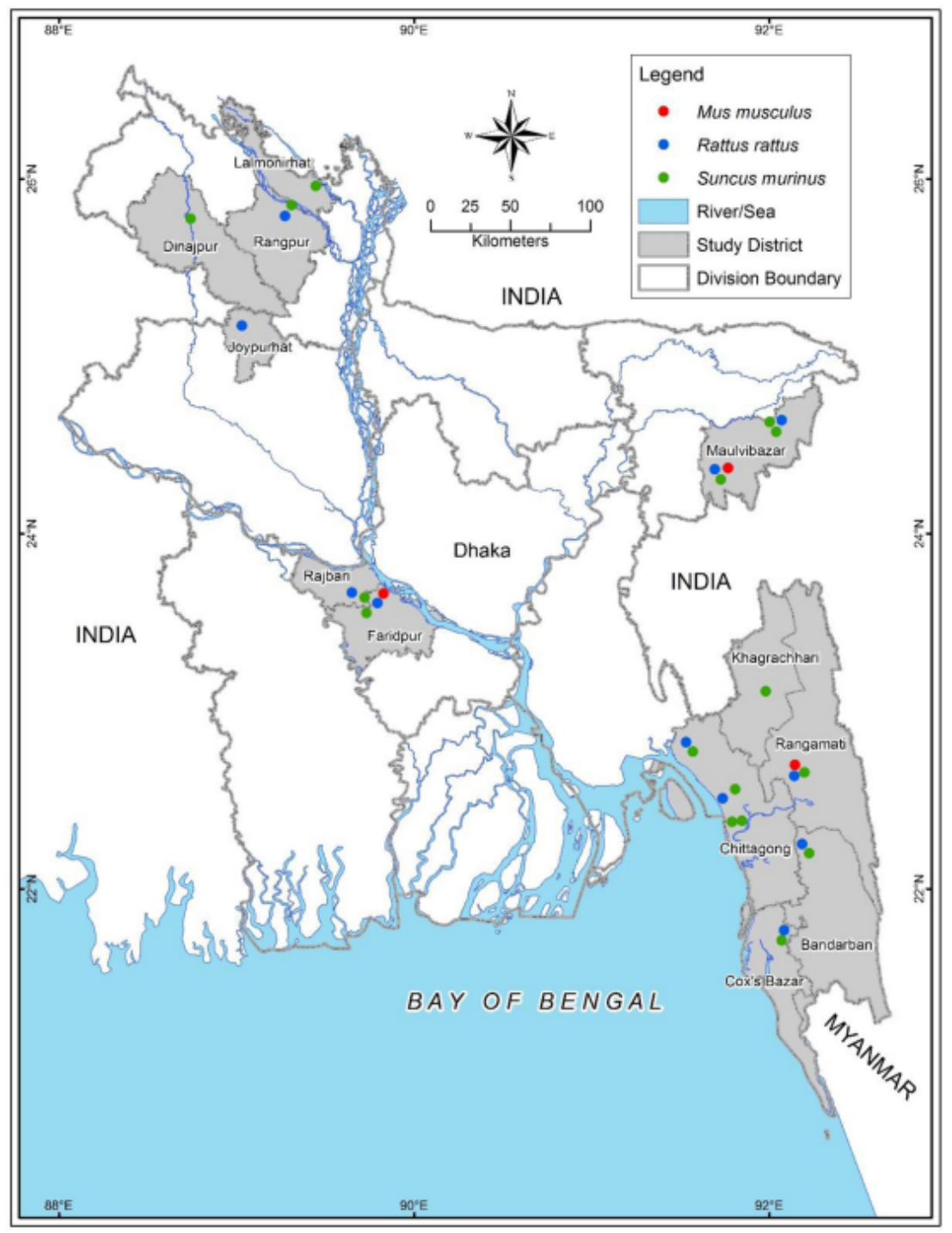

Figure 1. Rodents and shrew capturing sites in Bangladesh.

The traps were baited with ghee-smeared biscuit and dried fish. The traps were set at dusk and collected at the next dawn (Rahman et al., 2018). Trapped rodents and shrews were anesthetized by isoflurane. All the rodents and shrews were identified based on their morphological characters (Aplin $e t$ al., 2003). Blood was collected from the suborbital sinus, tail vein, or saphenous vein based on the size of each animal. A total of 451 rodents and shrews consisting of 299 S. murinus, $125 \mathrm{R}$. rattus, and $27 \mathrm{M}$. musculus were captured. The geographic area, the land gradient, and the animals' species, age, and gender were recorded. Male $(\mathrm{n}=83 ; 55 \%)$ and adult $(\mathrm{n}=131 ; 86 \%)$ rodents were prevalent among the captured animals. In contrast, females $(\mathrm{n}=166 ; 56 \%)$ and adult ( $\mathrm{n}=278 ; 93 \%)$ were predominant in captured shrews. Maximum number $(\mathrm{n}=61 ; 40 \%)$ of rodents and shrews were captured from the rural area.

\section{Laboratory examination}

All blood analyses were conducted at the clinical pathology laboratory, Chattogram Veterinary and Animal Sciences University (CVASU), Bangladesh. A thin blood smear was prepared with a small drop of blood. The slides were air-dried and fixed by absolute 
methanol for 3-5 minutes and stained with Giemsa at pH 7.1 (Thanee et al., 2009). The stained blood smears were examined under 1000X magnification using immersion oil, and approximately 200 fields of vision were inspected for the identification of blood parasites (Siñski et al., 2006; Thanee et al., 2009). Blood parasite identification was done based on the morphology of different stages of the parasites (Thanee et al., 2009).

\section{Ethical declaration}

The study protocol was approved by the Animal Experimentation Ethics Committee of CVASU (approval no. CVASU/Dir (R and E) AEEC/2015/07) and International Centre for Diarrheal Disease Research, Bangladesh (icddr,b; protocol: 2008-074) and IACUC of the University of California, Davis (protocol: 16048).

\section{Statistical analysis}

All the collected data regarding age, sex, species, and location were entered into MS excel-2007 (Microsoft Corporation, Redmond, WA 98052-6399 USA). Data analysis were done by STATA/IC-13 (StataCorp, 4905, Lakeway Drive, College station, Texas 77845, USA). Descriptive statistics were performed based on species of mammals, age, sex and land gradient. The results were expressed in percentage and 95\% Confidence Interval (CI).

\section{RESULTS}

The study identified Anaplasma spp., Babesia spp. and Plasmodium spp. in tested rodents and shrews (Figure 2). Altogether, $13 \%(58 / 451)$ of captured mammals were harboring hemoprotozoa in their blood, among which $7.5 \%(\mathrm{n}=34)$ were Anaplasma spp., 4.7\% (n=21) were Babesia spp. and rest $0.67 \%(\mathrm{n}=3)$ were Plasmodium spp.

Higher prevalence of hemoprotozoa were found in shrews $(14.38 \% ; n=299)$ than in rodents (9.87\%; $\mathrm{n}=152)$. $S$. murinus showed a higher percentage of blood parasitism ( $\mathrm{n}=43 ; 14.4 \%$; 95\%CI: 11-19) than $R$. rattus $(\mathrm{n}=14 ; 11.2 \%)$ and $M$. musculus $(\mathrm{n}=1 ; 3,7 \%)$. Among three parasites, Anaplasma spp. was most prevalent in shrews (10.03\%; $95 \mathrm{CI}$ :
7-14), whereas Babesia spp. was most prevalent in $R$. rattus (5.6\%; 95\% CI: $2-11$ ). Plasmodium spp. (2.4\%; 95\% CI: 1-7) was found only in $R$. rattus (Table 1). The only positive $M$. musculus was a male adult animal from the peri-urban area, which harbored Babesia spp. (Table 1).

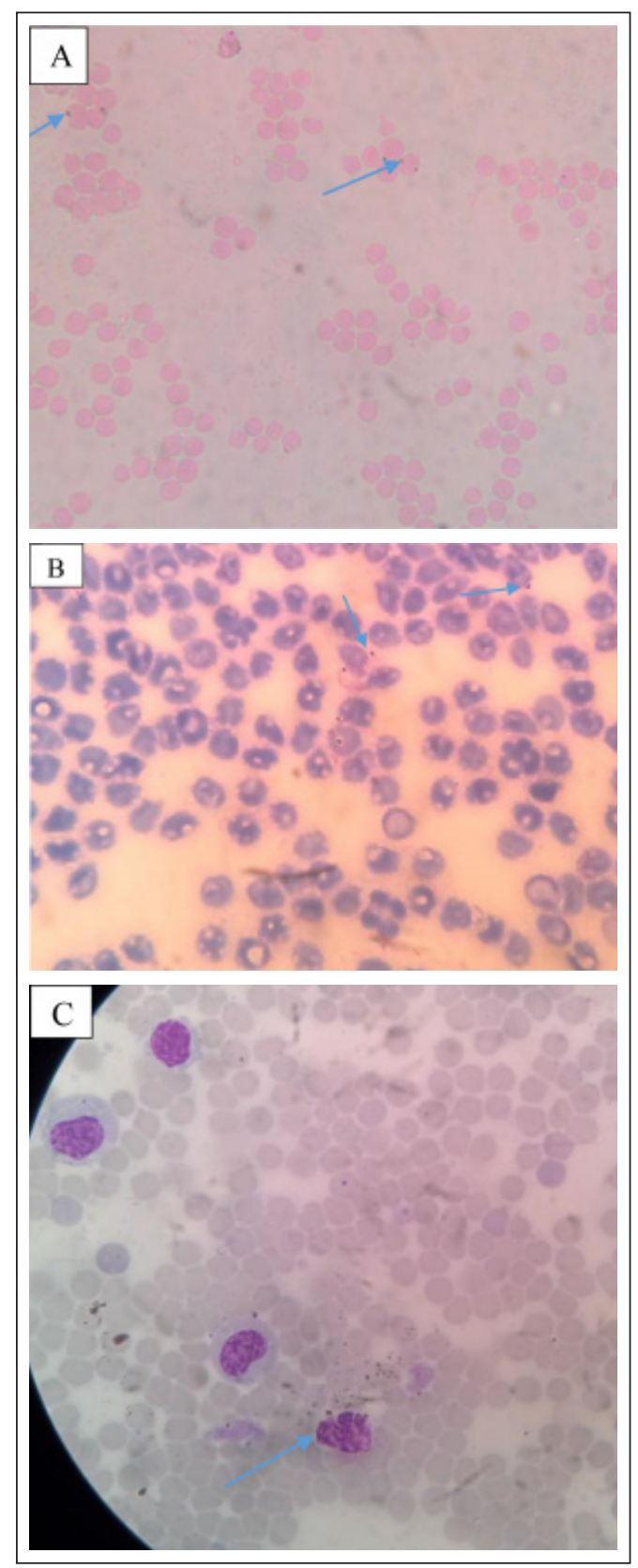

Figure 2. (A) Anaplasma spp., (B) Babesia spp. and (C) Plasmodium spp. found in microscopic examination of blood smear from rodents and shrews from Bangladesh. 


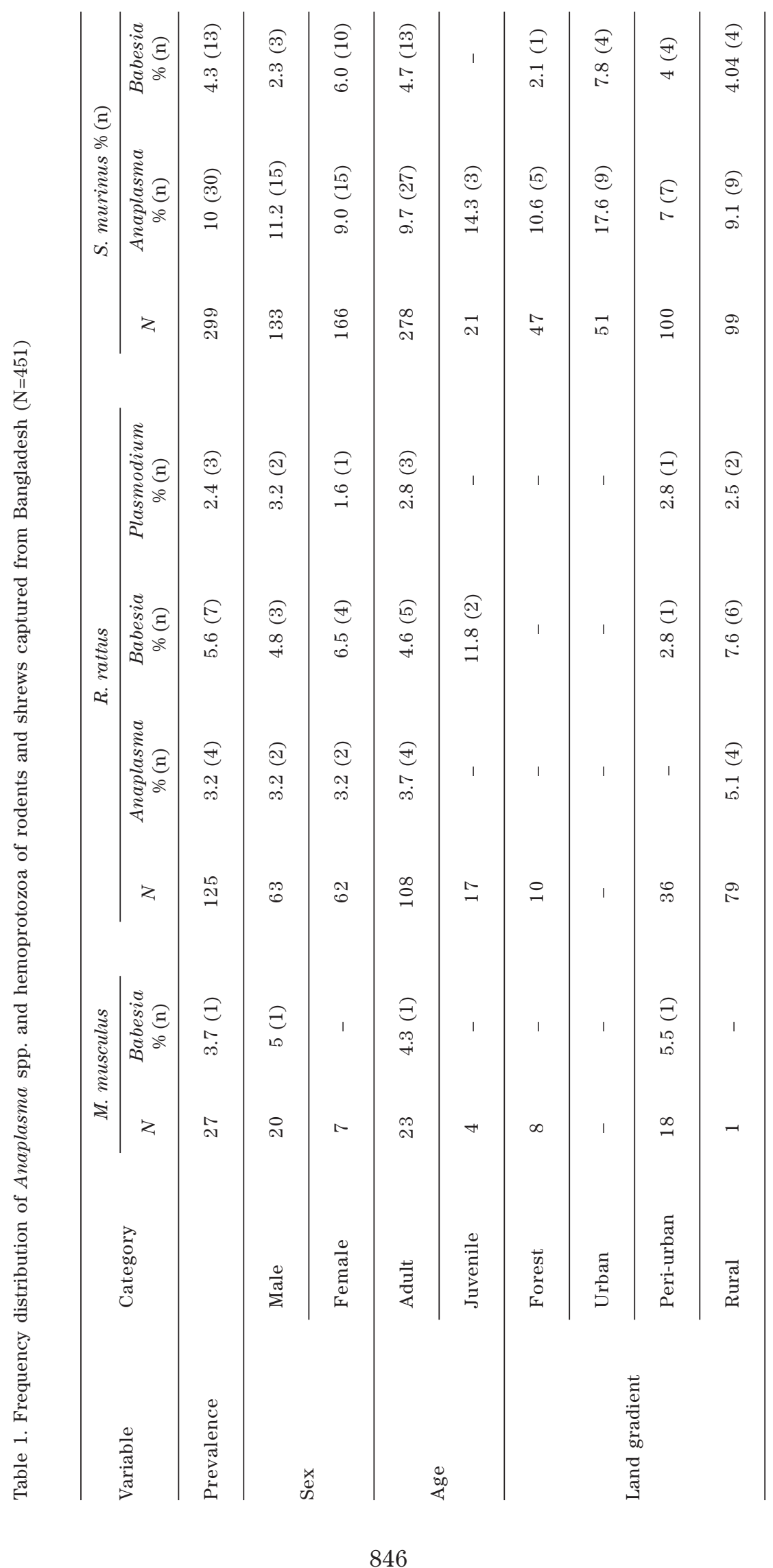


All three parasites were found in $R$. rattus. Babesia spp. and Plasmodium spp. were found in a greater percentage among females (6.5\%) and male (3.2\%) animals, respectively. Positive animals were mostly of adult age. In peri-urban areas, Babesia spp. (2.8\%, $\mathrm{n}=1,95 \%$ 0.07-15) and Plasmodium spp. (2.8\%, $\mathrm{n}=1,95 \%$ 0.07-15) were found at equal percentages, whereas in a rural area, Babesia spp. (7.6\%, $\mathrm{n}=6,95 \% 3-16)$ was more prevalent than the other two parasites (Table 1).

No plasmodium spp. was detected in house shrews. Males (11.2\%, $\mathrm{n}=15,95 \%$ 6-18) were more infected by Anaplasma spp. whereas females $(6.0 \%, \mathrm{n}=10,95 \% 3-11)$ were more infected with Babesia spp. Shrews were captured from all landscape gradients. But the detected two hemoprotozoa were higher in urban areas (Table 1).

\section{DISCUSSION}

The diversity of blood parasites found in rodents and shrews of this study could not be neglected. Blood parasites of rodents and shrews have not been previously reported from Bangladesh, and this information is important for human health, as well. Altogether, $13 \%$ of captured mammals were harboring hemoprotozoa, which includes $14.38 \%$ of shrews, and $9.87 \%$ of rodents. A previous study conducted on domestic rats in Nigeria found $16 \%$ prevalence of hemoprotozoa (Dada, 2016). Besides, 22.9\% prevalence of hemoprotozoa in rodents has been reported from Tanzania (Katakweba, 2018). Another study conducted on small mammals on the borderland of boreal and temperate forest zones found $32.5 \%$ of common shrews, and $41.2 \%$ of Eurasian water shrews were infected with blood parasites (Karbowiak et al., 2005). Moreover, rodents and shrews from selected localities in Tanzania and Swaziland reported 31.3\% and $1.33 \%$ prevalence of blood parasites, respectively (Katakweba et al., 2012). The variation in the percent positive is likely due to geographical difference, species of parasites identified, availability and distribution of tick vector in the study area, methods used to detect and identify the parasites (Katakweba, 2018).

Among different hemoprotozoa identified, 7.5\% were Anaplasma spp., $4.7 \%$ were Babesia spp. and $0.67 \%$ were Plasmodium spp. The prevalence of hemoprotozoa in rats (11.2\%) is lower than the findings by Ajayi et al. (2006) from Nigeria (63.08\%). This is also true for mice, in which $3.7 \%$ prevalence was found, comparatively lower than the previous report (Ajayi et al., 2006; McDonogh et al., 2015). Rats can be infected by Plasmodium spp. following the infective bite of Anopheles mosquito. The study presented here found a higher Babesia spp. prevalence in rats compared to mice, in contrast to a previous study in Lahore, which found greater prevalence and higher in mice than rats (Ahmad et al., 2011). Anaplasma spp. was found in a higher percentage (10.03\%) in shrew, which is similar to previous reports (Bray et al., 2007), whereas Babesia spp. was found higher in the rat in this study. Some investigators reported Babesia spp. as a rare parasite in rodents (Wiger, 1979).

Anaplasma spp. was found only in adult rats, which may be due to their diverse feeding habits, making them more prone to parasitic infections. Male and juvenile shrews were more infected by Anaplasma spp. in this study. Multiple factors like abundance and population structure of the tick vector, the climatic, and ecological features, including the sampling period, might be considered for the variation in parasitism (Matei et al., 2018). Anaplasma spp. is transmitted by multiple tick species, including genus Ixodes which are available in Bangladesh (Roy et al., 2018). Further detailed epidemiological investigations are required to determine the vector tick species and pathogen carried by ticks in Bangladesh.

Male and adult mice were parasitized more with Babesia spp., which corresponds to a prior study (Habicht et al., 1983). Hemoprotozoa were observed only in mice captured from peri-urban areas. The presence of Babesia spp. in rats was higher in females, in the juvenile animals, and rural areas. Similarly, Babesia spp. was also found in female shrews from urban areas. Higher 
percentage of adult animals (7.6\%) were parasitized by Babesia spp. in this study. A study conducted in the Indo-Chinese peninsula found a similar pattern for helminth infection on Murid rodents (Chaisiri et al., 2015). Older hosts get more expose and acquire the parasite infections than juveniles. Moreover, for foraging and breeding purpose, adult animals exposed in the large area that gives more opportunity to come in contact with infective stages of parasites (Rossin et al., 2009; Kataranovski et al., 2011).

Plasmodium spp. infection was higher in male rats and only found in adults. The percentage of Plasmodium spp. was similar in both peri-urban and rural areas, and no infection was found in the shrew. Plasmodium spp. infection was also recorded in the urban rat population in Peninsular Malaysia (43.3\%) (Alias et al., 2014). The present study reported the prevalence of Plasmodium as $0.67 \%$, though there is no significant variation in relation to sex and age, but a higher prevalence found among males.

In this study, Plasmodium, Babesia, and Anaplasma species were identified based on morphological characters under a compound microscope using a blood smear. But there are some inherent limitations. It was sometimes challenging to distinguish Babesia from the early stage of trophozoite (ring form) of Plasmodium parasites (Teal et al., 2012). Usually, less than $1 \%$ of erythrocytes become parasitized in the early course of infection that may cause missing of parasites in the blood smear. Molecular characterization of the organisms should be done for confirmation. Although Babesia spp. is zoonotic, but only limited species are responsible for this. However, the findings of this study will enrich the literature and can be used as a baseline for future research on hemoprotozoa in house shrews and rodents. Further research with larger sample size and molecular characterization is highly recommended for a better understanding of the ecology, epidemiology, and risk factors of hemoprotozoal infection in rodents and shrews.
Acknowledgements. This study was made possible by the support of the American people through the United States Agency for International Development (USAID) Emerging Pandemic Threats PREDICT project (cooperative agreement number GHN-A-OO-09-00010-00). Sincere thanks to the Faculty of Veterinary Medicine, Chattogram Veterinary and Animal Sciences University for their ethical permission and laboratory facilities. We thank Bangladesh Forest Department and the Ministry of Environment and Forest for permission to conduct this study. Cordial thanks to icddr,b, and its core donor, the Governments of Australia, Bangladesh, Canada, Sweden, and the UK for providing unrestricted support to icddr,b. We acknowledge to Jonathan $\mathrm{H}$ Epstein, Melinda K Rostral, Kevin J Olival, Peter Daszak, Emily S Gurley, Najmul Haider, Tapan Kumar Dey, Abdul Hai, Pitu Biswas and Gafur Sheikh for their contributions to this study.

\section{Conflict of Interests}

The authors declare that they have no conflict of interests.

\section{REFERENCES}

Ahmad, M.S., Maqbool, A., Mahmood-ulHassan, M., Mushtaq-ul-Hassan M. \& Anjum, A.A. (2011). Rodents as reserviors of babesiosis in urban areas of Lahore. The Journal of Animal and Plant Sciences 21: 2011-171.

Ajayi, O., Ogwurike, B. \& Ajayi, J. (2006). Blood protozoan parasites of rodents in Jos, Plateau State, Nigerai. Animal Production Research Advances 2: 202207.

Alias, S., Sahimin, N., Edah, M. \& Mohd-Zain, S. (2014). Epidemiology of blood parasitic infections in the urban rat population in Peninsular Malaysia. Tropical Biomedicine 31: 230-240. 
Aplin, K.P., Brown, P.R., Jacob, J., Krebs, C.J. \& Singleton, G.R. (2003). Field methods for rodent studies in Asia and the Indo-Pacific. Australian Center for International Agricultural Research, Camberra (Accessed on 05 August 2020). Available from: file://C:/Users/shari/ Downloads/100.pdf).

Arai, S., Song, J.-W., Sumibcay, L., Bennett, S.N., Nerurkar, V.R., Parmenter, C., Cook, J.A., Yates, T.L. \& Yanagihara, R. (2007). Hantavirus in northern short-tailed shrew, United States. Emerging Infectious Diseases 13: 1420.

Ayala, S.C., D'Alessandro, A., Mackenzie, R. \& Angel, D. (1973). Hemoparasite infections in 830 wild animals from the eastern Llanos of Colombia. The Journal of Parasitology 59: 52-59.

Bray, D., Bown, K., Stockley, P., Hurst, J., Bennett, M. \& Birtles, R. (2007). Haemoparasites of common shrews (Sorex araneus) in Northwest England. Parasitology 134: 819-826.

Chaisiri, K., Siribat, P., Ribas, A. \& Morand, S. (2015). Potentially zoonotic helminthiases of murid rodents from the IndoChinese peninsula: impact of habitat and the risk of human infection. Vector-Borme and Zoonotic Diseases 15: 73-85.

Criado-Fornelio, A., Ruas, J., Casado, N., Farias, N.A.R., Soares, M., Müller, G., Brum, J.G.W., Berne, M.E.A., BulingSaraña, A. \& Barba-Carretero, J. (2006). New molecular data on mammalian Hepatozoon species (Apicomplexa: Adeleorina) from Brazil and Spain. Journal of Parasitology 92: 93-99.

Dada, E.O. (2016). Study on the ectoparasites and haemoparasite $\mathrm{s}$ of domestic rats in parts of Akure South Local Government Area of Ondo State. International Journal of Clinical Chemistr y and Laboratory Medicine 2: 1-5.

De Lima, H., Rodríguez, N., Borges, R. \& Convit, J. (2003). Trypanosoma (Herpetosoma) lewisi in Rattus spp. from La Matica, Lara State, Venezuela and the possible relationship with zoonotic diseases. Boletín de Malariología y Salud Ambiental 43: 37-43.
Ellis, B., Regnery, R., Beati, L., Bacellar, F., Rood, M., Glass, G., Marston, E., Ksiazek, T., Jones, D. \& Childs, J. (1999). Rats of the genus Rattus are reservoir hosts for pathogenic Bartonella species: an Old World origin for a New World disease? The Journal of Infectious Diseases 180: 220-224.

Favorov, M.O., Kosoy, M.Y., Tsarev, S.A., Childs, J.E. \& Margolis, H.S. (2000). Prevalence of antibody to hepatitis E virus among rodents in the United States. The Journal of Infectious Diseases 181: 449-455.

Gorenflot, A., Moubri, K., Precigout, E., Carcy, B. \& Schetters, T. (1998). Human babesiosis. Annals of Tropical Medicine \& Parasitology 92: 489-501.

Gratz, N. (1994). Rodents as carriers of disease,, in rodent pests and their control, ed. by Buckle AP and Smith RH. CAB International, Oxford, p. 85-108.

Habicht, G.S., Benach, J.L., Leichtling, K.D., Gocinski, B.L. \& Coleman, J.L. (1983). The effect of age on the infection and immunoresponsiveness of mice to Babesia microti. Mechanisms of Ageing and Development 23: 357-369.

Kallio, E.R., Begon, M., Birtles, R.J., Bown, K.J., Koskela, E., Mappes, T. \& Watts, P.C. (2014). First report of Anaplasma phagocytophilum and Babesia microti in rodents in Finland. Vector-Borme and Zoonotic Diseases 14: 389-393.

Karbowiak, G., Rychlik, L., Nowakowski, W. \& Wita, I. (2005). Natural infections of small mammals with blood parasites on the borderland of boreal and temperate forest zones. Acta Theriologica 50: 3142.

Katakweba, A.A.S. (2018). The prevalence of haemoparasites in rodents and shrews trapped from domestic and peridomestic houses in Morogoro Municipality, Tanzania. A Hidden Public Health Threat. Tanzania Veterinary Journal 36: 75-82.

Katakweba, A.A., Mulungu, L.S., Eiseb, S.J., Mahlaba, T.A.A., Makundi, R.H., Massawe, A.W., Borremans, B. \& Belmain, S.R. (2012). Prevalence of haemoparasites, leptospires and 
coccobacilli with potential for human infection in the blood of rodents and shrews from selected localities in Tanzania, Namibia and Swaziland. African Zoology 47: 119-127.

Kataranovski, M., Mirkov, I., Belij, S., Popov, Z., Petroviæ, Z., Gačić, Z. \& Kataranovski, D. (2011). Intestinal helminths infection of rats (Ratus norvegicus) in the Belgrade area (Serbia): The effect of sex, age and habitat. Parasite 18: 189-196.

Kijlstra, A., Meerburg, B., Cornelissen, J., De Craeye, S., Vereijken, P. \& Jongert, E. (2008). The role of rodents and shrews in the transmission of Toxoplasma gondii to pigs. Veterinary Parasitology 156: 183190.

Laakkonen, J., Lehtonen, J.T., Ramiarinjanahary, H. \& Wright, P.C. (2003). Trypanosome parasites in the invading Rattus rattus and endemic rodents in Madagascar. Aciar Monograph Series 96: 37-39.

McDonogh, T.L., Thompson, P.P., Sangster, C.R., Meagher, P.J. \& Vogelnest, L. (2015). Hematologic and biochemical reference values of the Australian Bush Rat (Rattus fuscipes). Journal of Wildlife Diseases 51: 795-799.

Matei, I.A., D’Amico, G., Ionică, A.M., Kalmár, Z., Corduneanu, A., Sándor, A.D., Fiț, N., Bogdan, L., Gherman, C.M. \& Mihalca, A.D. (2018). New records for Anaplasma phagocytophilum infection in small mammal species. Parasites \& Vectors 11: $1-6$.

Nava, S., Lareschi, M. \& Voglino, D. (2003). Interrelationship between ectoparasites and wild rodents from northeastern Buenos Aires Province, Argentina. Memórias do Instituto Oswaldo Cruz 98: $45-49$.

Poláčiková, Z. (2013). Ecology of mites (Acarina) on small mammals (Eulipotyphla, Rodentia) in Podunajská nížina plain. Biologia 68: 162-169.
Rahman, M., Islam, S., Masuduzzaman, M. Alam, M., Chawdhury, M.N.U., Ferdous, J., Islam, M.N., Hassan, M.M., Hossain, M.A. \& Islam, A. (2018). Prevalence and diversity of gastrointestinal helminths in free-ranging Asian house shrew (Suncus murinus) in Bangladesh. Veterinary World 11: 549.

Raj, S., Ghazali, S.M. \& Hock, L.K. (2009). Endo-parasite fauna of rodents caught in five wet markets in Kuala Lumpur and its potential zoonotic implications. Tropical Biomedicine 26: 67-72.

Renapurkar, D. (1988). Suncus murinus. Observations on ecology, distribution, status to plague in Bombay. Journal of Hygiene, Epidemiology, Microbiology, and Immunology 33: 45-49.

Rossin, M.A., Malizia, A.I., Timi, J.T. \& Poulin, R. (2010). Parasitism underground: Determinants of helminth infections in two species of subterranean rodents (Octodontidae). Parasitology 137: 15691575.

Roy, B.C., Krücken, J., Ahmed, J.S., Majumder, S., Baumann, M.P., Clausen, P.H. \& Nijhof, A.M. (2018). Molecular identification of tickborne pathogens infecting cattle in Mymensingh district of Bangladesh reveals emerging species of Anaplasma and Babesia. Transboundary and Emerging Diseases 65: 231-242.

Sebek, Z. (1975). Blood parasites of small wild mammals in Czechoslovakia. Folia Parasitologica 22: 11-20.

Shafiyyah, C.S., Jamaiah, I., Rohela, M., Lau, Y.L. \& Aminah, F.S. (2012). Prevalence of intestinal and blood parasites among wild rats in Kuala Lumpur, Malaysia. Tropical Biomedicine 29: 544-550.

Singla, L.D., Singla, N., Parshad, V.R., Juyal, P.D. \& Sood, N.K. (2008). Rodents as reservoirs of parasites in India. Integrative Zoology 3: 21-26. 
Siński, E., Bajer, A., Welc, R., Pawełczyk, A., Ogrzewalska, M. \& Behnke, J.M. (2006). Babesia microti: prevalence in wild rodents and Ixodes ricinus ticks from the Mazury Lakes District of North-Eastern Poland. International Journal of Medical Microbiology 296: 137-143.

Sumangali, K., Rajakaruna, R. \& Rajapakse, R. (2007). Ecto and endo parasites of rodents from two selected sites in Kandy District. Peradeniya University Research Sessions Purse 2007, Volume 12 Part IAgricultural, Biological and Medical Sciences Editorial Board 44, 86.

Teal, A.E., Habura, A., Ennis, J., Keithly, J.S. \& Madison-Antenucci, S. (2012). A new real-time PCR assay for improved detection of the parasite Babesia microti. Journal of Clinical Microbiology 50: 903-908.

Thanee, N., Kupittayanant, S. \& Pinmongkholgul, S. (2009). Prevalence of ectoparasites and blood parasites in small mammals at Sakaerat Environmental Research Station, Thailand. Thai Jourmal of Agricultural Science 42: 149-158.
Veciana, M., Chaisiri, K., Morand, S. \& Ribas, A. (2012). Helminths of the Asian house shrew Suncus murinus from Cambodia. Cambodian Journal of Natural History 2: 115-122.

Wang, H., Yoshimatsu, K., Ebihara, H., Ogino, M., Araki, K., Kariwa, H., Wang, Z., Luo, Z., Li, D. \& Hang, C. (2000). Genetic diversity of hantaviruses isolated in China and characterization of novel hantaviruses isolated from Niviventer confucianus and Rattus rattus. Virology 278: 332-345.

Wiger, R. (1979). Seasonal and annual variations in the prevalence of blood parasites in cyclic species of small rodents in Norway with special reference to Clethrionomys glareolus. Ecography 2: 169-175.

Yadav, P.D., Vincent, M.J. \& Nichol, S.T. (2007). Thottapalayam virus is genetically distant to the rodent-borne hantaviruses, consistent with its isolation from the Asian house shrew (Suncus murinus). Virology Journal 4: 80. 